\title{
50. EFFECT OF DRILL STRING MOVEMENT ON SHAPE OF THE HOLE AND ON THE CORED ROCKS AT HOLE 459B'
}

\author{
T. J. G. Francis, Institute of Oceanographic Sciences, Wormley, Surrey, United Kingdom
}

\begin{abstract}
The caliper log run in semi-indurated sediments and rocks in Hole 459B revealed variations in hole diameter that can be used to reconstruct the effects of drill string movement on the shape of the hole. The hole drilled was not a perfect cylinder, but was generally funnel-shaped with sides sloping inward at about $0.004^{\circ}$. Lateral oscillations of the bit during drilling produced an enlarged hole whose diameter exceeded that of the bit by a couple of inches (ca. $5 \mathrm{~cm}$ ). By and large, the hole diameter was greatest in the softest rock. In places, further enlargement of the hole occurred repeatedly every 9.5 meters (the length of a core), caused primarily by sea-water erosion during the pumping of fresh core barrels down the pipe. Other portions of the hole were reamed smooth by the top edge of the bottom-hole assembly. Some recovered rocks show helical exterior grooves indicating that the drill bit not only rotated, but also moved in a small circle as the cores were cut.
\end{abstract}

\section{INTRODUCTION}

The caliper arm attached to the density logging tool measured the diameter of Hole 459B from 512 meters to 139 meters below the sea floor. The rocks encountered in this section were turbidites, ranging from marly chalks and mudstones to sandstones (see site report, this volume). The site is located at the eastern edge of the Mariana fore-arc region, just west of the trench-slope break (Fig. 1). The record obtained by the caliper is interesting not because of what it tells us about the rocks themselves, but because it clearly contains a great deal of information about the movement of the drill string in the hole and how this has affected the shape of the hole which was ultimately logged.

The reader is referred to the introductory chapter of this volume for information on coring procedures. Pertinent to the discussion here are the diameter of the drill bit $(9 \% / 8$ in.) and the length of the bottom-hole assembly $(121 \mathrm{~m})$ used at this site. The bottom-hole assembly consists of heavy lengths of drill collars, as they are called, whose weight can be partially or completely applied to the bottom of the hole for drilling. The bit contains four cones studded with tungsten carbide inserts, which rotate on separate bearings, providing the action necessary for coring. Cored material enters the center of the bit between the cones through a 2.5 -in. orifice. Cuttings are washed from the bottom of the hole to the sea bed by sea water circulated down the pipe, and through four jets in the core bit. In Hole 459B, coring was continuous, resulting in one core every 9.5 meters. A summary of the operations in the hole is given in the relevant site report in this volume.

\section{THE SHAPE OF THE HOLE}

The caliper log contains information on both a coarse and a fine scale. Consider first the overall shape of the

\footnotetext{
${ }^{1}$ Initial Reports of the Deep Sea Drilling Project, Volume 60.
}

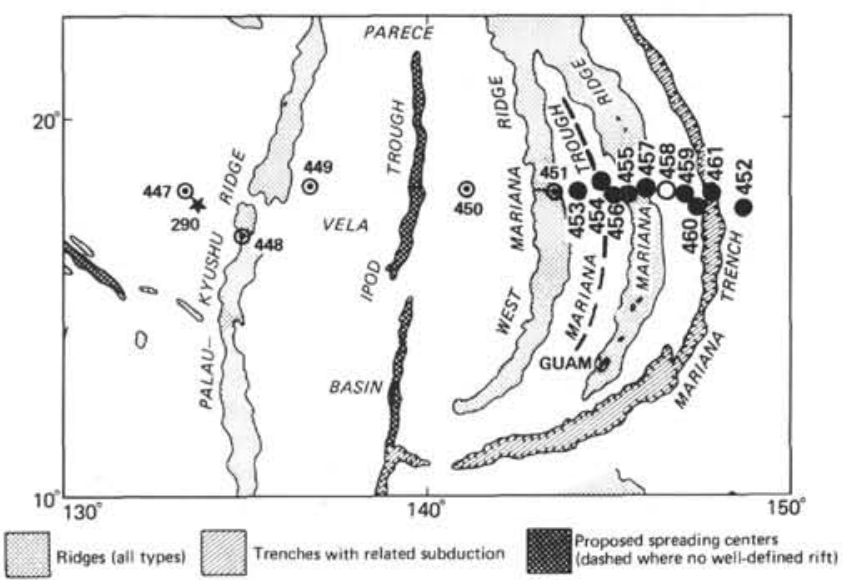

Figure 1. Location of Site $459(\mathrm{O})$ and other sites ( $)$ drilled during Leg 60 .

hole. In Figure 2, the hole radius is plotted against depth below the sea floor. The hole is not a perfect cylinder, but a highly elongated funnel whose sides slope inward at an average angle of $0.004^{\circ}$. The caliper log says nothing, of course, about the deviation of the axis of the hole from the vertical. Spot measurements were occasionally made of the deviation of the Glomar Challenger holes from the vertical during Leg 60 and were generally found to be less than $2^{\circ}$ (R. Knapp, personal communication).

Superimposed on the overall shape is a long-wavelength oscillation whose wavelength is roughly equal to the length of the bottom-hole assembly $(121 \mathrm{~m})$. This may be fortuitous, as bands of hard and soft rock, indicated by the drilling rate, alternate down the section with a comparable wavelength (Fig. 2). The zones of maximum hole diameter correlate with the softest rock, indicated by the highest drilling rates, except where soft rock is encountered immediately beneath harder rock. Where harder rock is encountered the tendency is for 


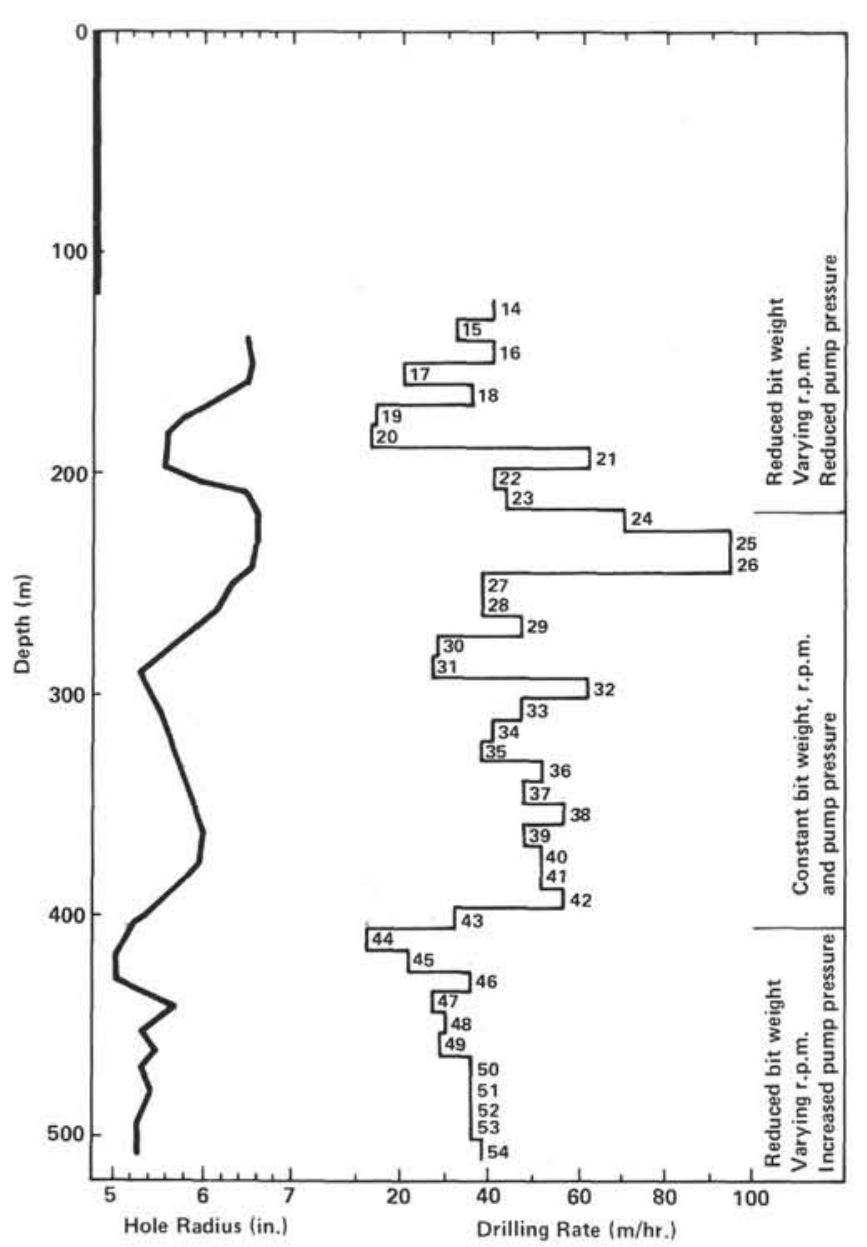

Figure 2. Radius of Hole 459B, measured by the caliper log, and drilling rate (with core numbers) plotted against depth below the sea floor. The drilling rate is inversely related to the hardness of the rock, provided that the weight on the bit, its speed of rotation, and the pump pressure do not vary greatly.

the hole to narrow, so that the minimum diameters are found near the bottom of hard bands (Cores 20,31, and 45).

In Figures 3 and 4, the radius of the hole is plotted against a larger vertical scale, so that the detail of its shape can be seen down to the limiting resolution of the caliper tool. The most conspicuous feature in both these figures is the overdeepening of the general envelope of the hole at 9.5 meter intervals down the hole. The bottom quarter of the bottom-hole assembly, terminating in the larger diameter bit release sub and the bit itself, is shown for comparison at the same horizontal exaggeration in Figure 3. Two sections of the hole, 208-248 meters (shown in Fig. 4) and 139-162 meters, were found to be remarkably smooth and devoid of the repetitive notches which were characteristic of most of the hole. These smooth sections occurred where the hole reached its greatest diameter of 13.0 to 13.2 inches.

\section{INTERPRETATION}

Many of the features of the shape of the hole described here can be accounted for by oscillations of the

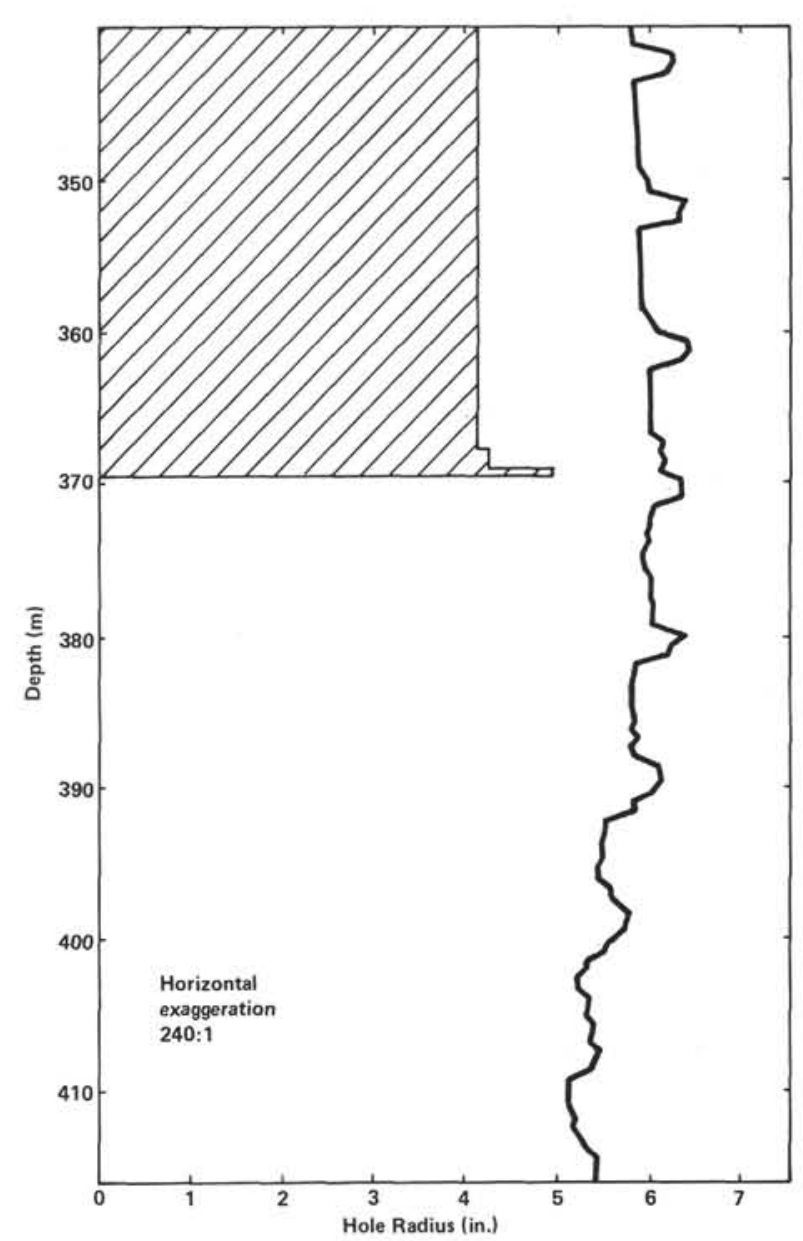

Figure 3. Profile of Hole 459B at depths from 340 to 416 meters obtained by the caliper tool. A section through the bottom-hole assembly, centered on the axis of the hole, is shown for comparison. Notice the clearance between the drill pipe and bit and the wall of the hole. Compare the dimensions of the drill bit with those of the notches occurring every 9.5 meters down the hole.

drill string during the drilling process. Before proceeding to describe these oscillations, it is necessary to summarize briefly relevant aspects of the drilling procedure.

When each 9.5-meter core has been cut, the drill string is raised by about one length of pipe and the core barrel is recovered on the sand line. When the barrel has reached the derrick floor the pipe is opened, the core barrel removed, and a fresh core barrel is dropped down the pipe. Additional pipe is then added, but only when the fresh core barrel has reached the bottom and latched in can the string be lowered and drilling recommenced. When sedimentary rocks are being drilled oceanic depths, much more time is spent manipulating core barrels than in the drilling itself. For the section of the Hole 459B considered here (Fig. 2), cores were recovered at an average rate of one every 105 minutes. But of this time only 17 minutes was spent in drilling. For most of the remaining 88 minutes the drill bit hung suspended approximately one pipe length above the bottom of the hole. The drilling time varied considerably with the hardness of the 


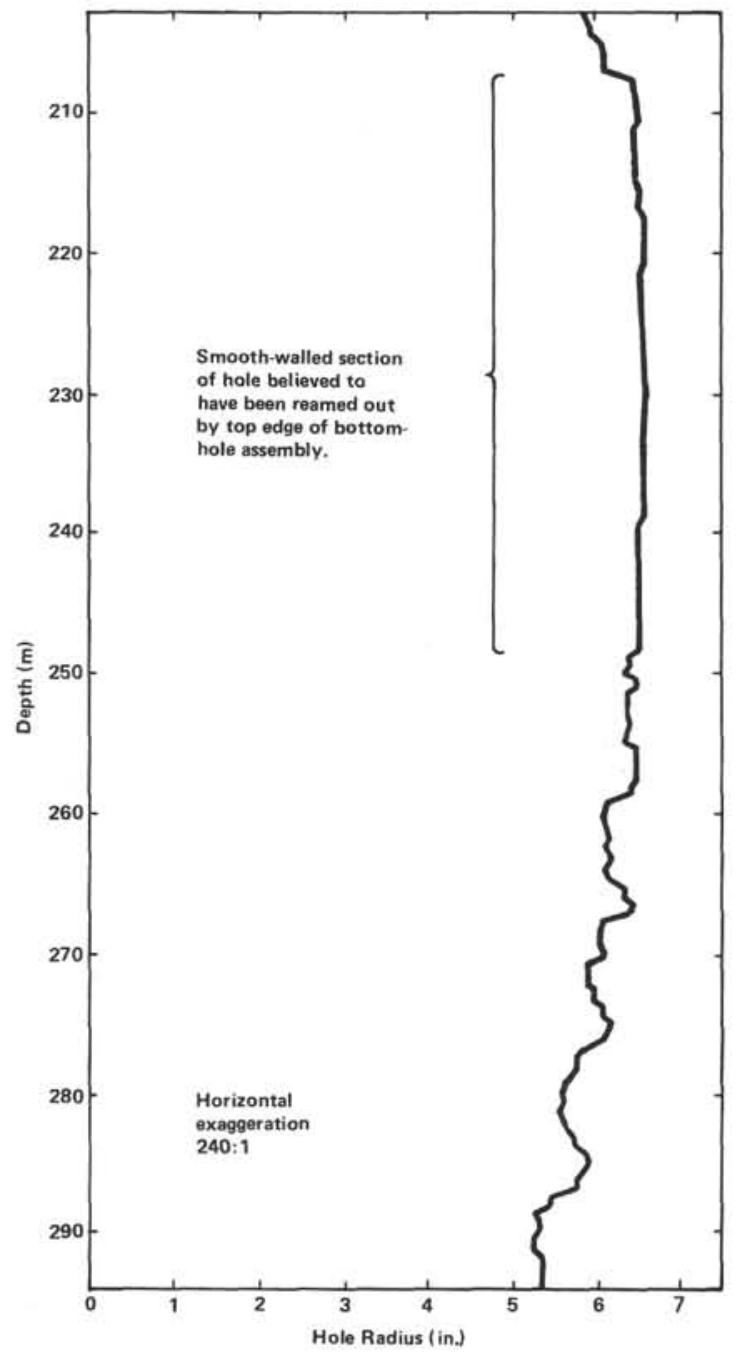

Figure 4. Profile of Hole 459B at depths from 203 to 294 meters obtained by the caliper tool. Notice the absence of notches between 208 and 248 meters.

rock, but the remaining time, being independent of the properties of the rock, was relatively constant.

During the cutting of a core, the drill string is rotated and water pumped down the pipe. For most of the sedimentary section of Hole 459B, the pumping rate was 10 strokes/min. (equivalent to $80 \mathrm{US}$ gal./min. or 303 $1 / \mathrm{min}$.). While core barrels are being manipulated the drill string is not rotated, but the fresh core barrel is pumped down the pipe at about $500 \mathrm{ft} . / \mathrm{min}$., which at Hole $459 \mathrm{~B}$ was equivalent to pumping at $347 \mathrm{gal} . / \mathrm{min}$. $(1314 \mathrm{l} / \mathrm{min}$.) for $30 \mathrm{~min}$.

In comparison to the slow and spasmodic progress of the drill string down the hole, its progress back up the hole is swift with but minor pauses. The pipe is pulled up and racked three stands at a time, so that only every 28.5 meters does the bit remain stationary in the hole. The duration of these pauses when pulling pipe is on the order of a minute.

Bearing in mind the drilling process as described here, let us now consider how the hole came to acquire its shape. A number of processes would appear to be involved:
1) The original drilling as each core is cut. Only when the motion of the drill bit is restricted to simple rotation about its axis as it moves down will this result in a cylindrical hole of minimal diameter (i.e., about $10 \mathrm{in}$.) ${ }^{2}$.

2) Subsequent reworking as the drill pipe moves in the hole. Softer rock is more likely to be reworked than harder, except where it occurs adjacent to harder bands which can protect it. At least two different modes of oscillation of the pipe are necessary to account for its shape.

3) Erosion of the hole or parts of it due to high velocities of the drilling fluid (sea water). This process could occur either when the core is being cut or when a fresh core barrel is being pumped down the pipe.

Let us consider in turn how different modes of oscillation and erosion could affect the shape of the hole. In order to describe the oscillatory movements of the pipe, let us define a system of perpendicular coordinates so that the axis of the hole is the $Z$ axis, and the $X$ and $Y$ axes lie along the sea floor.

\section{Vertical Oscillation of the Pipe End}

Lister (1964) has shown that a suspended wire system in the sea acts as a lightly damped mechanical oscillator driven by the heave of the ship. From observations of a pinger suspended at a depth of $4.5 \mathrm{~km}$, he deduced that the vertical motion of the end of the wire was three times greater than that of the ship. Amplification by as much as five times appears possible if the natural frequency of the wire system is well matched by the frequency of the swell.

The drill string suspended beneath the Glomar Challenger is a similar resonant system. The computer model of the dynamic response of the drill string to heave, currently in use at DSDP, indicates amplifications at the bottom of the string up to about two times (S. Serocki, private communication, 1979). Thus, when the drill string is suspended "stationary" for the retrieval of a core, the bit will in fact be oscillating vertically with an amplitude that could exceed the heave of the ship. Assuming that the latter is produced by a monochromatic swell of period $\tau$, the vertical oscillation of the bit can be described by

$$
Z=Z_{o} \cos \frac{2 \pi t}{\tau}
$$

These vertical oscillations coupled with sideways movements of the pipe could produce the repetitive notching shown in Figures 3 and 4 . Nowhere does the depth of a notch into the wall of the hole exceed the excess of radius of the drill bit over the bit release sub (0.69 in.). Thus the vertical width of a notch is the sum of the bit's vertical displacement and its own length $(0.4 \mathrm{~m})$. Measurement of the notches shows that the maximum vertical displacement of the drill bit $\left(2 Z_{o}\right)$ was in places very large.

\footnotetext{
2 In keeping with Glomar Challenger practice, the vertical scale in the hole is given in meters, the horizontal in inches $(1$ inch $=2.54 \mathrm{~cm})$.
} 


\begin{tabular}{cc}
\hline Location of Notch $(\mathrm{m})$ & $2 Z_{o}(\mathrm{~m})$ \\
\hline 285 & 7 \\
398 & 6 \\
415 & 8 \\
\hline
\end{tabular}

Vertical displacement of the drill bit by this amount seems excessive for the sea conditions prevailing at Hole 459B. Furthermore, if such large displacements had occurred during core cutting, they would have been too great for the three bumper subs included in the bottomhole assembly to absorb. This would have caused the bit to bounce on the bottom of the hole which, if it had occurred, would have been noticeable to the drillers. (The heave compensator was not employed for the sedimentary section of the hole). Thus, although some vertical oscillation of the bit must have been occurring, to rely solely on this process to account for the width of the notches implies vertical displacements of the bit that seem excessive. Nevertheless, it is interesting to compute the peak velocity and peak acceleration at the drill bit due to such large vertical oscillations. Taking $Z_{o}=4$ meters and $\tau=10$ seconds, these are:

and

Peak velocity $2 \pi Z_{o} / \tau=2.5 \mathrm{~m} \mathrm{~s}^{-1}$ Peak acceleration $4 \pi^{2} Z_{o} / \tau^{2}=0.16 \mathrm{~g}$.

This acceleration is about four times that of the maximum logged by downhole accelerometers at Hole $8 \mathrm{~A}$, Leg 2 (Peterson, Edgar, et al., 1969).

\section{Lateral Oscillation of the Bottom-hole Assembly}

The bottom-hole assembly, constructed from heavywalled drill pipe and collars, is considerably more rigid than the standard pipe making up the drill string. It is also short $(121 \mathrm{~m})$ in comparison with the length of standard pipe $(\sim 4000 \mathrm{~m})$. Any flexing of the bottomhole assembly is therefore negligible. But the drill string as a whole must flex considerably in response to stresses imposed by horizontal currents in the ocean and to the ship not being perfectly positioned over the hole. Thus it will hang only roughly vertically, and its rigid bottom end is likely to find itself at a small angle to the axis of the hole. On rotation, the motion of the bottom-hole assembly will be constrained by the narrowest part of the hole in which it finds itself. The drill bit will rotate about its axis, while at the same time its mid-point moves in a small circle:

and

$$
\begin{aligned}
& x=a \sin 2 \pi f t \\
& y=a \cos 2 \pi f t .
\end{aligned}
$$

Here $f$ is (most likely) the rate of rotation of the drill string, whilst $a$ could become as large as 1 to 2 inches $(2.5-5.0 \mathrm{~cm})$ (estimated from Fig. 3). Although the amplitude of this oscillation is much smaller than that of the vertical oscillation, the maximum acceleration it can produce is comparable because of the higher frequency involved. Taking $f=60 \mathrm{rpm}=1 \mathrm{~s}^{-1}$ (an upper limit to the rate of rotation) and $a=2.5 \mathrm{~cm}$, then the maximum lateral acceleration $=4 \pi^{2} f^{2} a=0.10 \mathrm{~g}$.
While the bottom end of the bottom-hole assembly moves in the small circle defined above, the top end describes a similar circle $180^{\circ}$ out of phase, of lesser or greater diameter depending on whether it is nearer or further from the constriction of the hole than the drill bit.

Lateral oscillation of the bottom-hole assembly of the type just described could build up whenever the drill string is rotating, and must be the chief cause of the excess diameter of the hole drilled. Furthermore, since much of the hole bears repetitive notches acquired during core retrieval (Figs. 3 and 4), much of this excess diameter must have been acquired during the core cutting stage. The implications of lateral oscillations of the bit on core recovery are examined in a subsequent section.

Not all of the excess diameter of the hole appears to have been acquired at this early stage, however. The profiles of the hole shown in Figures 3 and 4 have other features which require explanation:

1. Why is the hole between 208 and 248 meters free from repetitive gouges, although the rock there is relatively soft?

2. Why is the hole between 310 and 367 meters, apart from the repetitive gouging, so smooth?

3 . Why are the repetitive gouges near 350 meters, where the rock is soft, no deeper than those near 410 meters where it is harder?

The simplest explanation to all these queries is that parts of the hole have been reamed out by the top edge of the bottom-hole assembly. The geometrical feasibility of this for the 208- to 248-meter depth range is shown in Figure 5. The process cannot occur where the diameter of the hole decreases with increasing depth. Reaming of the hole between 310 and 367 meters can explain not only its smooth profile, but the limited depth of the repetitive gouges. Removal of the bottom part of originally Gaussian shaped notches could also explain why the notches near 350 meters are different in shape from those near 400 meters (Fig. 3).

\section{Erosion of the Hole by Sea Water}

Sea water pumped down the drill pipe and back up the outer part of the hole acquires velocities at certain stages of its journey that are sufficient to cause erosion, especially of the softer sedimentary rocks. Two distinct rates of pumping were employed during the drilling of the sedimentary section of Hole 459B: approximately $303 \mathrm{l} / \mathrm{min}$. during the core cutting stage and about 1314 $1 / \mathrm{min}$. when pumping down fresh core barrels. With the bit used at this hole, the water pumped down the pipe passed into the hole through four 0.5 -inch-diameter orifices between the cones. Thus, the lower pumping rate produced a downward water velocity through these jets of $10.0 \mathrm{~m} / \mathrm{s}$ ( $20 \mathrm{knots} / \mathrm{s}$ to the nautically minded) and the higher some four times as great. Water moving at these speeds is very erosive. However, by the time the water flows back through the annulus between the bit and the wall of the hole it has slowed considerably, and it is the velocity here which determines whether enlargement of the hole will take place. If the drill bit is simply 


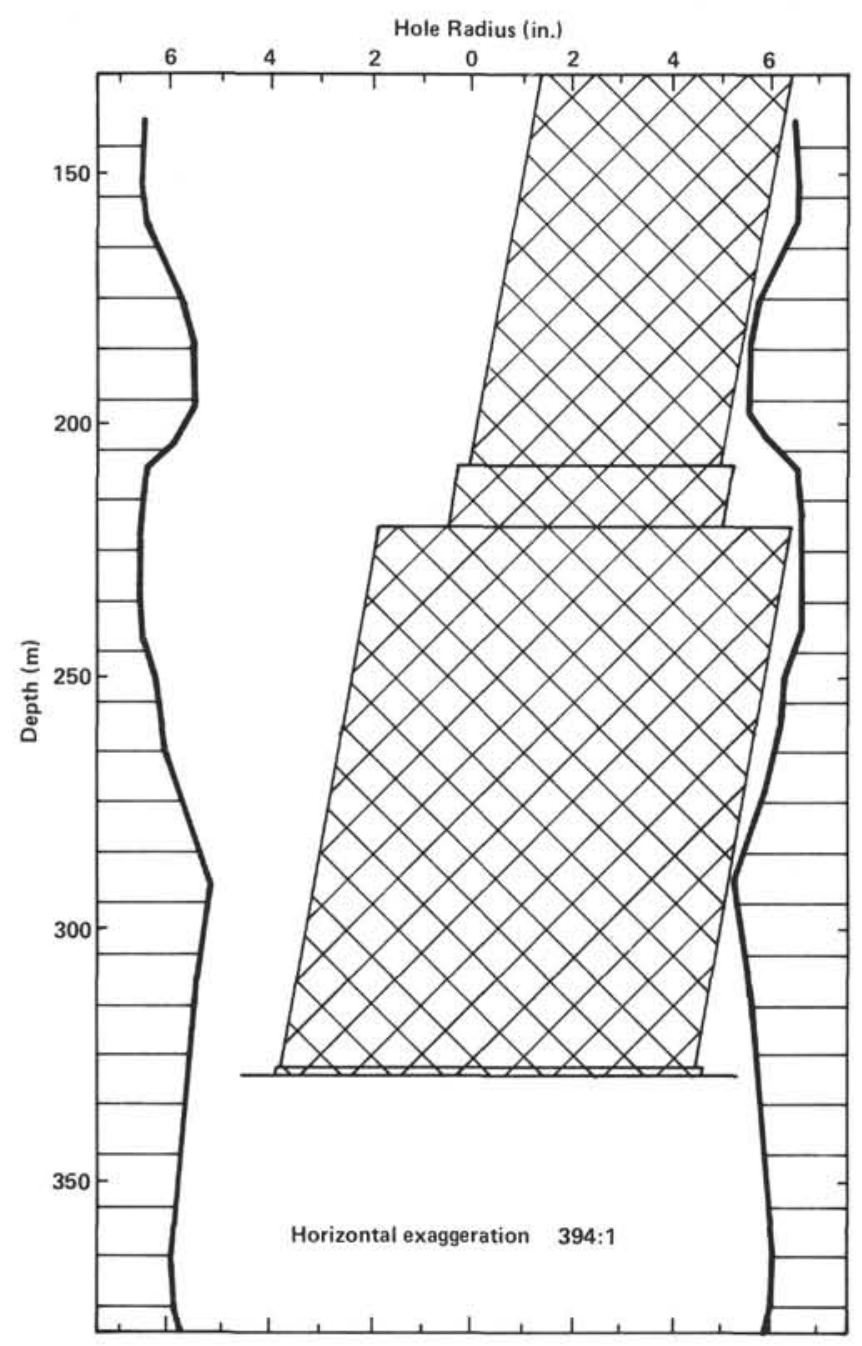

Figure 5. The bottom 200 meters of the drill string shown at large horizontal exaggeration within the profile of Hole 459B to demonstrate how the top edge of the bottom-hole assembly could have reamed out the hole between 208 and 248 meters.

rotating about its axis as it penetrates the rock, the initial clearance between the bit and the wall of the hole will be small. Water velocity at this stage of the drilling might be sufficient to produce some enlargement. However, by the time the clearance has grown to, say, 0.5 inches, the water velocities through the annulus between the bit and the wall of the hole will already have fallen to $1.0 \mathrm{~m} / \mathrm{s}$ and $4.3 \mathrm{~m} / \mathrm{s}$, respectively, for the two rates of pumping.

How much the water erodes the wall of the hole is a function of time as well as of velocity. Water flowing up the hole with velocity $v$ will produce a drag force per unit area on the wall of the hole proportional to $v^{2}$. The power required to produce this flow will be proportional to $v^{3}$ and the energy expended per unit area of the wall of the hole in time $t$ will be proportional to $v^{3} t$. It seems reasonable to assume that the rate of erosion of a particular area of the hole wall is proportional to the power being expended there, and the total amount of erosion to the total energy. This simple argument makes it possible to assess the relative importance of water erosion in the vicinity of the drill bit during the core cutting and the core manipulation stages of drilling.

At Hole 459B, core cutting of the sedimentary section proceeded at a rate of about $50 \mathrm{~m} / \mathrm{hr}$. (Fig. 2). Since the large-diameter part of the drill bit is only 0.4 meters long (Fig. 3), the drill bit effectively passes any point on the wall of the hole in about half a minute. During the core manipulation stage the drill bit remains stationary (neglecting heave-drive vertical oscillations) at a given point in the hole for approximately 30 minutes, while the fresh core barrel is pumped down the pipe. Since the water velocities during the two stages for a particular hole diameter vary by a factor of 4.3 , the relative importance of erosion during the two stages of drilling is given by:

$$
\frac{v_{2}{ }^{3} t_{2}}{v_{1}{ }^{3} t_{1}}=\frac{4.3^{3} \times 30}{0.5}=4770 \text {. }
$$

The foregoing argument suggests that erosion of the hole by water is only significant when fresh core barrels are being pumped down the pipe. This supports the conclusion drawn in the previous section that the chief cause of hole enlargement is lateral oscillation of the rotating drill string as each core is cut. Furthermore, if water erosion were important during core cutting one would expect the envelope of the hole to follow the drilling rate more closely than it does (Fig. 2). For example, from Cores 32 through 35 the drilling rate indicated that the rocks were getting harder, but over the same interval the diameter of the hole increased. Only at a wavelength comparable to the length of the bottom-hole assembly does the envelope of the hole follow the variations in rock hardness.

\section{Evidence for Oscillation of the Bit during Drilling}

The different conditions prevailing during the cutting of a core than during its retrieval have already been discussed. The shape of the hole measured by the caliper log provides evidence for drill string oscillations principally during the time when the cores are being retrieved. Evidence for movement of the drill bit while the core is being cut is more difficult to come by, but was provided at Hole 459B by the cored rocks themselves. Some of the cores recovered were marked with righthanded helical grooves down their cylindrical surfaces. A particularly good example is shown in Figure 6 . If the drill bit were simply rotating about its axis as it penetrated the rock, the cores obtained would be smoothsided cylinders. The presence of helical grooves gives a quantitative measure of the other types of motion affecting the bit.

It has long been known that many of the cores recovered by the Glomar Challenger exhibit disturbance acquired during the drilling process. Kidd (1978) has discussed how core-discing affects the internal structure of cores. The sculpting of the curved surface of cores described here produced no disruption of their internal structure because the rock was sufficiently strong to resist it. 
The core sample shown in Figure 6 contains six complete spirals of average wavelength $0.9 \mathrm{~cm}$. While these were being cut, the core must still have been attached to bedrock and vertical oscillations of the bit have been negligible. The rotation rate of the string during cutting of Core 39 was $40 \mathrm{rpm}$, hence the wavelength of the spirals indicates a drilling rate of 0.36 meters minute. This is only about half that determined from the time taken to drill the complete core $(0.79 \mathrm{~m} / \mathrm{min}$.), but variations of this order from the average rate could easily be encountered.

Of greater interest is how the regular helical grooves came to be formed in the first place by a drill bit (in excellent condition at this stage of the hole) that under normal conditions produces a smooth cylindrical core. The necessary condition for this is that the bit not only rotated but moved in a small circle. This is the same type of motion as that identified in the foregoing:

$$
\begin{aligned}
& x=a \sin 2 \pi f t \\
& y=a \cos 2 \pi f t
\end{aligned}
$$

but of much smaller amplitude. The depth of the grooves $(1 \mathrm{~mm})$ is a measure of the amplitude; thus $a \cong$ $0.5 \mathrm{~mm}$. Again $f$ is probably the rate of rotation of the drill string, although higher harmonics of this frequency might be encountered. If $f$ were twice the rate of rotation, the drilling rate indicated by the helical grooves would agree closely with the average rate for the core.

In conclusion, therefore, when the bottom of the core being cut is still attached to its host rock, the non-

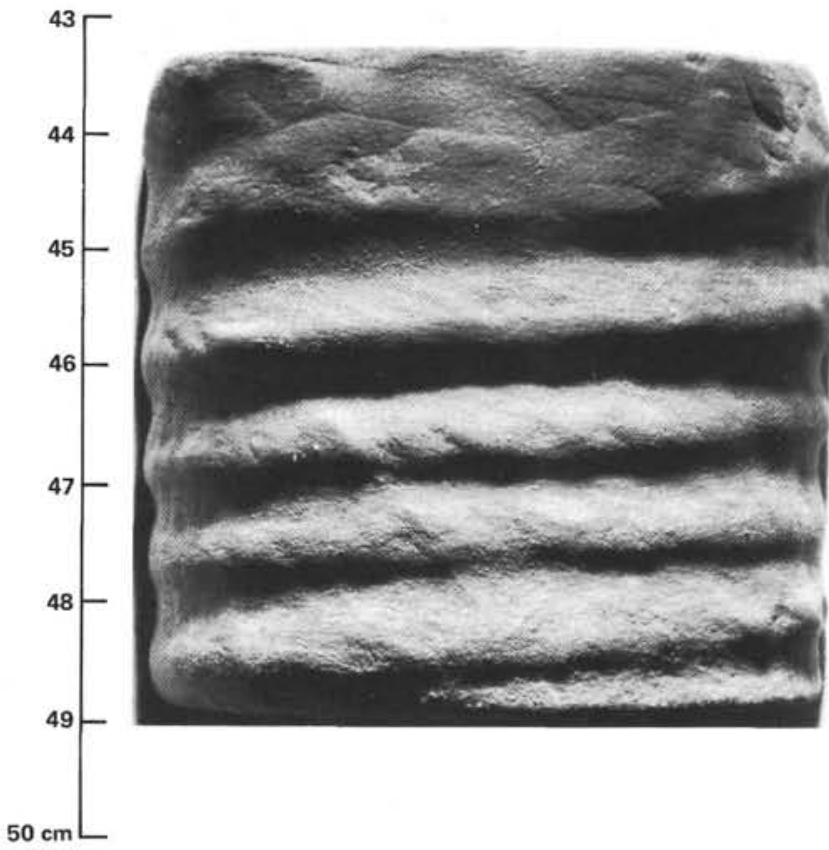

Figure 6. Siltstone (Sample 459B-39-1, 106-111 cm) showing righthanded helical grooves. The latter indicate that the drill bit was oscillating laterally during drilling with an amplitude of $0.5 \mathrm{~mm}$, giving 1-mm-deep grooves. rotatory oscillations of the drill bit are either small or negligible. In this situation the bit will drill a regular cylindrical hole with a diameter only slightly larger than that of the bit itself, say 10.0 inches. Occasionally, however, lateral or vertical oscillations might build up which will snap off the rock being cored and result in the core recovered being broken up into a series of short pieces. Quite small lateral oscillations could achieve this, whereas for the bit to lift off the bottom of the hole requires vertical oscillation of the bottom of the drill string in excess of what can be accommodated by the bumper subs. Furthermore, when the rock core in the drill bit is not attached to bedrock, lateral oscillations of the bit could build up more easily. It seems therefore that lateral oscillation of the drill bit might be of more importance to the drilling process than vertical oscillations.

Sustained lateral oscillations of the drill bit of only a few millimeters amplitude would tend to break up lithified rock and thus inhibit core recovery. This might be the chief cause of poor recovery in Glomar Challenger drilling.

\section{CONCLUSIONS}

Oscillatory movements of the drill string during the drilling of a hole in the ocean floor by the Glomar Challenger plus some erosion of the wall by the drilling fluid-sea water-result in an enlarged hole of complex shape. Analysis of the profile of Hole 459B and of the shape of cored samples has shown that the following processes are involved.

1. Drilling of a cylindrical hole only slightly larger in diameter than the bit.

2. Drilling of an enlarged hole due to lateral oscillations of the drill bit induced by the string rotation. Lateral oscillations of only a few millimeters amplitude would inhibit core recovery.

3. Erosion of the wall of the hole in the vicinity of the drill bit by the sea water pumped through the hole as each fresh core barrel is emplaced. Heave-induced vertical oscillations of the bit at this stage of the drilling process add to the length of hole over which this erosion takes place.

4. Reaming of parts of the hole, where the diameter increases or is constant with increasing depth, by the top edge of the bottom-hole assembly.

\section{ACKNOWLEDGMENTS}

I thank Swede Larson, Jim Natland, and Stan Serocki of DSDP for helpful discussions and comments. Joe Cann, Rob Kidd, and Drummond Matthews kindly reviewed the manuscript.

\section{REFERENCES}

Kidd, R. B., 1978. Core-discing and other drilling effects in DSDP Leg 42A Mediterranean Sediment Cores. In Hsü, K., Montadert, L., et al., Init. Repts. DSDP, 42, Pt. 1: Washington (U.S. Govt. Printing Office), 1143-1149.

Lister, C. R. B., 1964. On the vertical motion of equipment lowered by wire into the deep sea. Bul. Inst. Pol. Din Iasi, Serie Noua, Tomul 10, Fasc 3-4, 87-96.

Peterson, M. N. A., Edgar, N. T., et al., 1969. Init. Repts. DSDP, 2: Washington (U.S. Govt. Printing Office). 